\section{Solvents for Ear Wax}

SIR,-I was very interested to read Dr. J. I. Horowitz's letter (30 November, p. 583). It was a very clever and painstaking way of finding out the best solvent. As chairman of the National Service Medical Board in Wrexham we found the following solution very effective. We used it from 1939 to 1959: sodium bicarbonate 15 gr. (1 g.); glycerin 3 drachms (12 g.), water to 1 ounce (28 ml.).

When any of the recruits were found with wax in their ears the otorhinolaryngologist concerned used to inject a few drops into the ears and apply cotton-wool, and when the recruit had completed his round of the other examiners he would return to the ear, nose, and throat room-say in about 20 to 30 minutes. The examiner would then gently syringe the car with a warm solution of sodium bicarbonate $1 \mathrm{drachm}(4 \mathrm{~g}$.) to a pint $(570 \mathrm{ml}$.) of warm water, pulling the auricle upwards and backwards.

We found this method invariably effective. I also had very little trouble when syringing ears in my practice using this solution. It was prescribed by the experts who compiled the instructions for the guidance of medical boards.-I am, etc.,

$$
\text { Dyserth }_{\text {Flintshire. HUGH G. MORRIS-JONEs. }}
$$

SIR,-As an author of one of the articles referred to by Dr. J. I. Horowitz (30 November, p. 583) on solvents for ear wax, may I be allowed to comment on the points he raises.

The difficulties of objective criteria in the clinical use of ear wax solvents were acknowledged, and in vitro tests were not in fact referred to, as in my opinion being open to similar objections. The problems of standardization of the wax sample for comparative purposes, avoiding cutting of the plug, thereby breaking up the harder surface layer, and control of ambient temperature are all initial difficulties to be overcome. Absence of agitation would be a necessary precaution in reproducing the in vivo conditions.

Further, the in vitro procedure differs from the in vivo in that complete liquefaction is not necessary; dissolution of the wax adherent to the skin of the external auditory meatus is all that is necessary for successful trauma-free syringing.

The semi-quantitative presentation adopted shows Xerumenex to be only somewhat less effective than the preparation he found the most satisfactory. While he concludes that all the other preparations were completely useless-including olive oil, which is contrary to generations of experience-this must be intepreted with the proviso that the wax plug he used for the test had been removed from the ear for six months, and represented very far from a natural state of affairs.

Finally, it is of interest to note that the presumed active principle of the effective preparation (dioctyl sodium sulphosuccinate) is the same in one of the least effective, though the solvents differ; details of the solvents are not given, other than that the less effective preparation is in an oil solution, and the effective in a water-miscible solution.-I am, etc.,

$$
\begin{gathered}
\begin{array}{c}
\text { Lightwater, } \\
\text { Surrey. }
\end{array} \\
\text { F. DE S. DonNaN. }
\end{gathered}
$$

\title{
Sir William Osler
}

SIR,-How many of your readers know (or remember) that 29 December 1968 is the 49th anniversary of the death of the great physician Sir William Osler? He was born at Bond Head, in Upper Canada, on "Orangeman's Day," 12 July 1849, and died at his home "The Open Arms," 13 Norham Gardens, Oxford, while holding the Chair of Regius Professor of Medicine, on 29 December 1919. In his last illness he was treated by the late Dr. Gibson, of Oxford, and the late Lord Horder, who incidentally gave a vivid account of the last illness (so far unpublished) in a paper to the Osler Club of London at the "Pneumonia Evening," held at the Medical Society of London, on 11 January' 1952. On that memorable occasion under the chairmanship of Sir Zachary Cope, when there was "standing

\section{Medical Assistants}

SIR,-I would like to compliment you on your leading article on the medical assistant grade (14 December, p. 657), and, while agreeing with you that a permanent subconsultant grade is necessary and will continue to be necessary in the National Health Service, I think it should be appreciated that the failure of the previous sub-consultant grades-i.e., S.H.M.O. and J.H.M.O.-and of the present medical assistant grade is due to the undoubted fact that, though theoretically it is possible to proceed to a consultant appointment, in fact there has always been so much prejudice against these grades that it has been rare for a person holding one to obtain a consultant post. In accident and

\section{Green Paper}

SIR,-Last night $I$ attended a meeting of our division to discuss the Green Paper. I left convinced that what we need is a unified tripartite system divided into four to take cognizance also of the needs of the occupational health service, so far completely ignored. The new administration will have

to be based on areas of varying sizes, with the proviso that, whatever the size, this will be too large for some purposes and too small for others. Or vice versa.-I am, etc.,

Romford, Essex. LeoN M. SHIRLAw.

\section{Recognition for Seniority}

SIR,-We have read a weight of correspondence in support of the General Medical Services Committee's condemnation of the Minister's intention to tie seniority awards to a minimum number of postgraduate attendances (Supplement, 5 October, p. 1). •

It is regrettable that this high-handed method was thought necessary, but a sad reflection on ourselves. Sixty years after $\mathrm{Sir}$ William Osler campaigned for postgraduate teaching in the county hospitals these facilities have now been made freely available, but only a small proportion of practitioners attend.

The same man said " that without postgraduate work a doctor was stale in five years, in the rut by ten, and by twenty in so deep he could never get out."1

Surely none of us would like to admit that he has so little interest in recent advances that he falls into the last category.-I am, etc.,

$$
\begin{aligned}
& \text { Morpeth, } \\
& \text { Northumberland. } \\
& \text { R. W. TUKE. } \\
& 1 \text { Cushing, Harvey, The Life of William Osler, } \\
& \text { 1925. Oxford. }
\end{aligned}
$$

\section{Organizing the A.R.M.}

SIR,-The next A.R.M. is only some seven months away. I think most will agree that events of the last few years have provided an absolute necessity of organizing the business of the meeting in a more efficient manner. The near chaos of last year has encouraged our enemies and worried our friends. Surely the meeting must be arranged to enable set debates on the most important subjects with perhaps spare time balloted for by divisions. May we hope that the organizing committee has some definite proposals to offer ?-I am, etc.,

London $\mathbb{W} .13$.

R. E. W. Oliver. 